FREITAS, Ramiro Ferreira de. Vamos humanizar a Constituição? Revista Eletrônica Direito e Política, Programa de Pós-Graduação Stricto Sensu em Ciência Jurídica da UNIVALI, Itajaí, v.12, n.3, $3^{\circ}$ quadrimestre de 2017. Disponível em: www.univali.br/direitoepolitica - ISSN 1980-7791

\title{
VAMOS HUMANIZAR A CONSTITUIÇÃO?
}

WILL WE HUMANIZE THE CONSTITUTION?

BRITTO, Carlos Ayres. O humanismo como categoria constitucional. 2. reimp. Belo Horizonte: Fórum, 2012. 124 p. ISBN 978-85-7700-088-3.

\section{Ramiro Ferreira de Freitas ${ }^{1}$}

SUMÁRIO: Introdução; 1 As Luzes são acesas para o bem da Humanidade Civilizada; 2 Democracia: um mundo fraterno; 3 O Humanismo na construção do Jurídico: o lado pessoal na revelação Justiça $X$ Direito; 4 Operadores do Direito: uma ponte entre o abstrato e o concreto; 5. A Constituição como Força Axiológica e Cetro da Energia Humanista legislada; Conclusão; Referências

\section{INTRODUÇÃO}

Trata-se, a presente recensão, de um breve comentário sobre a obra $O$ humanismo como categoria constitucional, do Professor Carlos Ayres Britto, exMinistro do STF (Supremo Tribunal Federal), membro da Academia Brasileira de Letras Jurídicas, conferencista e renomado advogado. Procuramos enfocar aspectos originais do lineamento teórico e sutilezas peculiares na construção do pensamento que transita entre contemplativo e concreto.

\section{AS LUZES SÃO ACESAS PARA O BEM DA HUMANIDADE CIVILIZADA}

O mundo ocidental não surgiu sem uma boa dose de crenças. Crer em Deus, depois na Ciência (como nova deidade) e nas Instituições é lugar-comum. Essa conclusão se torna clara a partir dos múltiplos sentidos na palavra "humanismo". O conhecimento (como busca do verdadeiro) está intelectualmente ligada a

\footnotetext{
1 Universidade Regional do Cariri - URCA (Faculdade de Direito, Campus São Miguel). Av. Teodorico Teles, 645 - São Miguel, Crato-CE, CEP: 63100-160. E-mail: ramiroferreira91@gmail.com
} 
FREITAS, Ramiro Ferreira de. Vamos humanizar a Constituição? Revista Eletrônica Direito e Política, Programa de Pós-Graduação Stricto Sensu em Ciência Jurídica da UNIVALI, Itajaí, v.12, n.3, $3^{\circ}$ quadrimestre de 2017. Disponível em: www.univali.br/direitoepolitica - ISSN 1980-7791

todas as derivações e menções relativas ao vocábulo. Seja ilustrando o culto à categoria humana (cultivo dos velhos idiomas) ou sua maturação, o pendor científico não pode ser negligenciado. Estudar e mentalizar vocações por modelo "douto" adjetiva uma sociedade instruída (focada nos bons hábitos e modos).

Conservadora é esta civilização, revela Britto $^{2}$, muitas vezes traída pelo colonialismo subjetivado, maleável impulso mantenedor para continuidade das regras no jogo histórico da política supostamente "liberal".

Como doutrina, o humanismo é conjunto de reverências à aventura dos sujeitos universais, trata o "animal político" oposto ao bom selvagem. Seria urgente mensurar papeis e formas claras de cognição. Positivamente, o instinto cede espaço, domando opções outrora válidas. "Da proclamação de que "o homem é a medida de todas as coisas" (Protágoras)", cujo efeito prático é explicar o estado atual (causal) das coisas, "ao "cógito" de René Descartes, passando pela máxima teológica de que todos nós fomos feitos à imagem e semelhança de Deus"3, restam as duvidosas lacunas existenciais. A pessoa humana é complexa. "Por isso que titular do "inalienável" direito de se assumir tal como é: um microcosmo."4 Os ingleses (1215) já planejavam dignificar para motivar (em 1628 o nexo parlamentar é revisitado na Bretanha), mas foram as Revoluções que mereciam conduzir ao novo patamar o originário caráter político - "O reino sobre o rei" - em favor dos rudimentos soberanos populares.

Nascimento livre e igual (art. 1 da Declaração de 1779) é antitípica fórmula para elencar direitos fundamentais amplificados. Obviamente, 0 tom social prevaleceria (Constituições de 1917 no México, por exemplo), embora fosse mera programação despida, nua para o crescimento das hegemonias científica e cultural. Sim, há um fundamento lógico que envolve todos em nós mesmos. Só o homem é portador do sublime dignitário ${ }^{5}$. A música literária dos cânticos universais - o todo é único porque está no corpo social - soa como melódica

2 BRITTO, Carlos Ayres. O humanismo como categoria constitucional. 2. reimp. Belo Horizonte: Fórum, 2012, p. 17.

3 BRITTO, Carlos Ayres. O humanismo como categoria constitucional, p. 20.

${ }^{4}$ BRITTO, Carlos Ayres. O humanismo como categoria constitucional, p. 20.

${ }^{5}$ BRITTO, Carlos Ayres. O humanismo como categoria constitucional, pp. 25-29. 
FREITAS, Ramiro Ferreira de. Vamos humanizar a Constituição? Revista Eletrônica Direito e Política, Programa de Pós-Graduação Stricto Sensu em Ciência Jurídica da UNIVALI, Itajaí, v.12, n.3, $3^{\circ}$ quadrimestre de 2017. Disponível em: www.univali.br/direitoepolitica - ISSN 1980-7791

aproximação entre o evolutivo e o aprovado. Ou seja, o consenso entre maiorias e minorias é simples: interação humana respondendo à qualidade vital coletiva. Fraternidade sonhada!

\section{DEMOCRACIA: UM MUNDO FRATERNO}

Quem ousaria negar o impacto das mudanças no imperativo democrático posterior à Segunda Grande Guerra? Preparos e exercícios soberanos dividem a regulação com o plural, o diverso. Ser diferente torna-se naturalístico. Inflam os microssistemas jurídicos: direito à informação, à ética, ao trabalho. Mas, na vanguarda, entender-se-á por status civilizatório o alcance positivista da participação (Constituições portuguesa de 1976 c/c Carta Brasileira de 1988) formalista, difusa materialmente, distributiva e reparatória contra injustiças. "Esse atualizado humanismo significa atribuir à humanidade o destino de viver no melhor dos mundos. A experimentar o próprio céu na terra, portanto." ${ }^{\text {. Por }}$ outro lado, conformação e vislumbre caótico da realidade jamais pareceram alternativa viável. O discurso fenomênico otimista é consolador e, simultaneamente, antipático, revelador dos medos e incertezas sem, contudo, nutrir esperanças permanentes. Viver no paraíso, mesmo ideal, transfigura refúgio, protege dos imediatos ciclos retóricos nefastos.

Bem-estar genérico, eis a máxima heteronomia do Direito. Só o Direito engendra os seres em estado social, só a barbárie oporá "lobos contra lobos" (lembrando o Leviatã). A bipolaridade Certo versus Errado exige comandos e ordena mandamentos exigíveis, sob pena das reprimendas em casos desobedientes. Não ligar para os radicalismos (art. 19, II da CF-88) e cumprir a lei: espectro do "bom" cidadão.

\section{O HUMANISMO NA CONSTRUÇÃO EFICAZ DO JURÍdICO: O LADO PESSOAL NA REVELAÇÃO JUSTIÇA X DIREITO}

Formulações regratórias estão aquém das necessidades reais. Poucos vivem confortavelmente e, para essa minoria, a maioria não tem, em si, repercussão.

${ }^{6}$ BRITTO, Carlos Ayres. O humanismo como categoria constitucional, p. 37. 
FREITAS, Ramiro Ferreira de. Vamos humanizar a Constituição? Revista Eletrônica Direito e Política, Programa de Pós-Graduação Stricto Sensu em Ciência Jurídica da UNIVALI, Itajaí, v.12, n.3, $3^{\circ}$ quadrimestre de 2017. Disponível em: www.univali.br/direitoepolitica - ISSN 1980-7791

As "gritantes" assimetrias oriundas da globalização tomam ideologia por subterfúgio: neoliberalismo. Denúncias reverberam, justamente conforme o ditado popularizado "Faça o que eu digo, não faça o que eu faço". Os países ricos fecham suas fronteiras, os pobres rechaçados assumem periferia, dispostos à cruenta hipoeconomia. Mas, não é só isso.

Construir uma sociedade justa, livre e solidária, garantir o desenvolvimento nacional, erradicar a pobreza/marginalização e reduzir as desigualdades sociais e regionais, promovendo o bem de todos, sem preconceitos nem discriminação, acha-se no pano de fundo vantajoso quando fala-se em república federativa (CF88), todavia cai na artimanha do ineficaz, viciado com severas camadas de negada efetividade. Desemprego, falta de educação, preconceitos, patrimonialismo, economia informal, "corte" de gastos públicos e lucros bancários subsistem concretamente. Ah, corrupção e roubo cínico das verbas públicas assumem tradição nos periódicos e nas fontes midiáticas massivas. Crescentes pressões geradas pelos ingredientes alhures, afora inúmeras outras, elevam transtornos no mais deslavado "cupim da república" (Ulysses Guimarães). São urgentes esforços e providências instituidoras da boa-fé comandada por Direito ético. Entrar na vida e sair da folha de papel.

Carlos Ayres Britto traça hipóteses na tentativa de "encurtar" o fosso entre o humanismo e situações quotidianas (Capítulo VII da obra, pp. 51-54). O segredo talvez resida no amor, afetivo sentimento genuíno pelo próximo (empregados, colegas, garçons, etc). Tratar os outros como gostaríamos de ser tratados (Kant).

Daí o analógico vínculo entre Humanismo e Justiça (abstrata e concreta). A concreta não existe segregada das especulações teóricas que the originaram. Ora, o constitucionalismo é discurso legislado simbólico. A lei - patamar primário - contém ponto inicial que, no mais das vezes, leva ao ponto de chegada. Resolver os liames concretos, entretanto, guarda sutilezas nem um pouco simplistas. Polissemia exige flexibilidade, pois o reducionismo entrincheirado não combina com o homem, indivíduo sentenciado à mutabilidade desde suas compreensões. 
FREITAS, Ramiro Ferreira de. Vamos humanizar a Constituição? Revista Eletrônica Direito e Política, Programa de Pós-Graduação Stricto Sensu em Ciência Jurídica da UNIVALI, Itajaí, v.12, n.3, $3^{\circ}$ quadrimestre de 2017. Disponível em: www.univali.br/direitoepolitica - ISSN 1980-7791

\section{OPERADORES DO DIREITO: UMA PONTE ENTRE O ABSTRATO E O CONCRETO}

As virtudes do Direito estão na complementaridade de suas partes. A primeira metade (concretude das formas) posta-se como reverberação do texto descritivo (legislado pré-decisional). Referido e referente sublinham justiça, ou, pelo menos, coesão. Ser e Dever-ser traduzem mútuas indagações, formuladas e residentes na vigência do convencimento interpretativo. O jurista, "ponte" entre enunciado e propositura efetiva, é mentalmente responsável pela "garimpagem" argumentativa (o cérebro alegórico, explicando dualidade fisiológica hemisférios quânticos, onda/partícula -) à luz das confusões entre sentimento e inteligência. (vide caps. IX a XII do escrito sob análise, pp. 59-85, com descobertas intuitivas).

\section{A CONSTITUIÇÃO COMO FORÇA AXIOLÓGICA E CETRO DA ENERGIA HUMANISTA LEGISLADA}

Nos últimos capítulos da obra resenhada (caps. XIII a XIX, pp. 87 et seq), Britto sinaliza o escopo primordial - o Constitucionalismo categorizado pelo Humanismo - filosoficamente, plasmando fatores injetados no âmbito valorativo das noções "justa resolução" e "ponderação" (termos já consagrados) perante diretrizes constitucionais dirigentes. Colecionando regulamentações programáticas, a governabilidade operacional do sistema jurisdiciza qualificações condutoras do imperativo centralizador. Estratégia fundamental dos poderes legitimadores inspirados nas Normas-Base aquinhoadas no respeito altruísta constitui política embutida nos protagonismos (mormente o judicial). Defesas e favorecimentos fazem dos grupos os virtuais "donos" de seus trajetos. Mínimo existencial sobrepuja reserva do possível, é questão de "honra humanista", humanitária e formalizada na vontade permanente da nação brasileira. A Lei Fundamental é superlativa no presente e no futuro, transcendendo gerações.

Governar o próprio governo: ultima ratio do projeto nacional nomeado Constituição de 1988. Mínimo existencial sobrepuja reserva do possível, vale a repetitiva ênfase, a sucessão geral dos interesses não se limita à momentânea restrição. Faz-se o que ordena a Constituição, depois o resto... 
FREITAS, Ramiro Ferreira de. Vamos humanizar a Constituição? Revista Eletrônica Direito e Política, Programa de Pós-Graduação Stricto Sensu em Ciência Jurídica da UNIVALI, Itajaí, v.12, n.3, $3^{\circ}$ quadrimestre de 2017. Disponível em: www.univali.br/direitoepolitica - ISSN 1980-7791

\section{CONSIDERAÇÕES FINAIS}

Enfim, nada dispensa a leitura integral do crítico, provocante e relevante livro. As interrelações entre o pensamento humanista hodierno e traços constitucionais firmes (no âmbito do Estado Democrático) ficam evidenciadas no processo (encadeamento de ideias) histórico que gerou modelos vigentes de legalidade superior - a ideia de Norma Fundamental do Sistema - e interesse fraterno pelos outros - preceituado arcabouço transformado em dirigentes promessas.

\section{REFERÊNCIA DAS FONTES CITADAS7}

BRITTO, Carlos Ayres. Teoria da constituição. Rio de Janeiro: Forense, 2003.

CANOTILHO, J. J. Gomes. Constituição dirigente e a vinculação do legislador: contributo para a compreensão das normas constitucionais programáticas. Coimbra: Coimbra Ed., 1994.

COMPARATO, Fábio Conder. Ética, direito, moral e religião no mundo moderno. São Paulo: Companhia das Letras, 2007.

GALVÃO, Paulo Braga. Os direitos sociais nas constituições. São Paulo: Ltr, 1981.

MELLO, Oswaldo Aranha Bandeira de. A teoria das constituições rígidas. São Paulo: J. Bushatsky, 1980.

ROUSSEAU, Jean-Jacques. O contrato social. Trad. Antônio de P. Machado, estudo crítico de Afonso Bertagnoli. Rio de Janeiro: Ediouro, 1997.

XIFRA-HERAS, Jorge. La constitución como norma y como ley. In: Revista de informação legislativa, v. 20, n. 80, pp. 53-102, out./dez. 1983.

Submetido em: julho de 2017

Aprovado em: agosto de 2017

\footnotetext{
7 As indicações bibliográficas refletem uma escolha de referencial teórico específica, utilizada pelo autor do livro ora resenhado. Não fiz consulta aos originais. O material aludido poderá ser empregado no desenvolvimento de vindouras abordagens mais substanciais e profundas quanto à matéria. A lista completa de textos citados por BRITTO (2012) está nas pp. 119-124 do ensaio monográfico.
} 